\title{
Oncology
}

\section{Cancer-Related Therapies at the End of Life in Hospitalized Cancer Patients from Four Swiss Cantons: SAKK 89/09}

\author{
Klazien W. Matter-Walstra ${ }^{a}$ c $\quad$ Rita Achermann ${ }^{e} \quad$ Roland Rapold $^{e} \quad$ Dirk Klingbiel $^{c}$ \\ Andrea Bordoni $^{f}$ Silvia Dehler ${ }^{g}$ Gernot Jundt ${ }^{b}$ Isabelle Konzelmann ${ }^{j}$ \\ Kerri Clough-Gorrd, h Thomas Szucs a, e Bernhard C. Pestalozzic, i \\ Matthias Schwenkglenks ${ }^{a}$

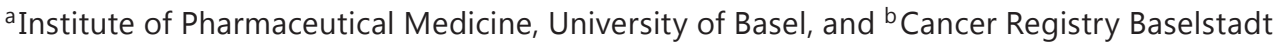 \\ and Baselland, University Hospital Basel, Basel, 'Swiss Group for Clinical Cancer Research \\ Coordinating Center, and Institute for Social and Preventative Medicine, University of Bern, \\ Bern, ${ }^{\mathrm{e}}$ Helsana Group, ${ }^{\mathrm{f} C a n c e r}$ Registry Ticino, Locarno, ${ }^{\mathrm{g} C a n c e r}$ Registry Zürich and Zug, \\ University Hospital Zürich, h National Institute for Cancer Epidemiology and Registration, \\ and ${ }^{i}$ Department of Oncology, University Hospital Zürich, Zürich, and ${ }^{j}$ Cancer Registry \\ Valais, Sion, Switzerland
}

\section{Key Words}

End of life $\cdot$ Cancer $\cdot$ Radiotherapy $\cdot$ Chemotherapy $\cdot$ Health insurance $\cdot$ Hospitalization

\begin{abstract}
The use of cancer-related therapies in cancer patients hospitalized at the end of life has increased in many countries over time. Given the scarcity of published Swiss data, the objective of this study was to evaluate the influence of hospital type and other factors on the delivery of health care during the last month before death. Claims data were used to assess health care utilization of cancer patients (identified by cancer registry data of four participating Swiss cantons) who deceased between 2006 and 2008. Primary endpoints were delivery of cancerrelated therapies during the last 30 days before death. Multivariate logistic regression assessed the explanatory value of hospital type, patient and geographic characteristics. Of 3,809 identified cancer patients in the claims database, 2,086 patients dying from cancer were hospitalized during the last 30 days before death, generating 2,262 inpatient episodes. Anticancer drug therapy was given in $22.2 \%$ and radiotherapy in $11.7 \%$ of episodes. Besides age and cancer type, the canton of residence and hospital type showed independent, statistically significant associations with intensity of care, which was highest in university hospitals. These results should initiate a discussion among oncologists in Switzerland and may question the compliance with standard of care guidelines for terminal cancer patients.




\section{Oncology}

\begin{tabular}{l|l}
\hline Oncology 2015;88:18-27 & \\
\hline DOI: 10.1159/000367629 & $\begin{array}{l}\text { @ 2014 S. Karger AG, Basel } \\
\text { www.karger.com/ocl }\end{array}$ \\
\hline
\end{tabular}

Matter-Walstra et al.: Cancer-Related Therapies at the End of Life in Hospitalized Cancer Patients from Four Swiss Cantons: SAKK 89/09

\section{Introduction}

Delivery of health care at the end of life of cancer patients has gained increasing attention during the last decade [1-5]. While the intensity of care in general seems to have increased over time [6-8], the appropriateness and quality of delivered care is increasingly discussed $[9,10]$. Furthermore, the results of studies show that care at the end of life is not uniformly delivered to all patients but is influenced by several demographic and geographic factors [11-13]. Why and to what degree these inequalities exist or if they should be a matter of concern is unclear. Demand- or supply-driven over- or undertreatment are difficult to distinguish in retrospective studies and prospective studies on end-of-life care are difficult to perform. Still, retrospective nationwide studies on how cancer patients are treated at the end of life may uncover existing disparities and can deliver important information to the oncologist community as well as policy makers in order to discuss the prevailing practice or effects of modification of such a practice.

The first large-scale study on end-of-life cancer care in four Swiss cantons was performed in 2011, using health insurance data for the delivery of care information (for patients deceased between 2006 and 2008) and cancer registry data to identify cancer patients [14]. This study revealed significant differences in the intensity of care during the last 30 days before death, between patients with different insurance types as well as between patients living in different cantons. One of the limitations of the primary analysis was that for some of the included patients (those without hospitalization during the last month before death) no information on the cause of death was available. This might have led to a dilution of the results, caused by patients who did not die from cancer. In addition, in this first analysis the effect of the type of treating hospital was not included. Therefore, we decided to perform a more in-depth analysis on the cohort of patients who were hospitalized during the last 30 days before death and had a known cancer-related cause of death. This analysis concentrates on the estimation of the effect different hospital types might have on the intensity of care given at the end of life.

\section{Patients and Methods}

A detailed description of the study methodology is given in a previous publication [14].

\section{Study Population}

The original retrospective study included patients aged 20 years or older at the time of cancer diagnosis, who died between 2006 and 2008, lived in one of the participating Swiss cantons, and had been customers of the Helsana Group insurance company for at least 1 year before death. In short, 3,809 patients from four cantons [Basel-Stadt/Basel-Landschaft (BS/BL; language German, one university hospital), Ticino (TI; language Italian, no university hospital), Valais (VS; language German and French, no university hospital) and Zurich (ZH; language German, one university hospital); Swissmap, 2001] were identified as being eligible and were included in the original study. During the last 30 days before death, 2,608 (68.5\%) of these patients were hospitalized in 49 different acute care hospitals. For 2,494 (96\%) of these patients, inpatient information was available and for 2,086 (83.6\%), hospitalization was cancer-related [defined as patients who had a primary admission diagnosis indicative of cancer, and/or had cancer-related symptom(s) or diseases, or had a non-cancer-related reason for admission but suffered from ongoing active cancer as described in the patient history]. The following analysis is based on these 2,086 patients. As some of the patients were hospitalized more than once in different hospitals, the study was based on the total episodes of hospitalizations $(n=2,262)$.

In- and Outpatient Delivered Care Information

Swiss claims data relating to inpatient episodes do not contain full details on the treatments and diagnostic procedures performed. Therefore, this information was collected from the patient records in the 


\section{Oncology}

\begin{tabular}{l|l}
\hline Oncology 2015;88:18-27 \\
\hline DOI: 10.1159/000367629 & $\begin{array}{l}\text { @ 2014 S. Karger AG, Basel } \\
\text { www.karger.com/ocl }\end{array}$ \\
\hline
\end{tabular}

Matter-Walstra et al.: Cancer-Related Therapies at the End of Life in Hospitalized Cancer Patients from Four Swiss Cantons: SAKK 89/09

hospitals. Information on outpatient care is available in detail in the Helsana claim database. Anticancer drug therapy (ACDT) is defined by the anatomical therapeutic chemical codes (online suppl. table S1; for all online suppl. material, see www.karger.com/doi/10.1159/000367629), and radiotherapy (RT) by TARMED reimbursement codes or as described in the patient record. TARMED is the Swiss tariff system for medical services provided to outpatients (Tarmed, 2006-2008).

\section{Outcomes and Covariates}

The primary endpoints of this study were indicators of the intensity of care delivered to cancer patients in the last 30 days before death, defined as the administration of ACDT, RT or ACDT and/or RT (D ${ }^{\text {ao }}$ RT). A distinction was made between purely inpatient and in- and/or outpatient (ANY) administered therapies as many therapies are delivered in the hospital but in an ambulatory setting. These endpoints were set in relation to the potential explanatory variables as described below.

The following patient characteristics were collected: age at death, gender, cancer type (colon, hematologic, lung, breast, prostate, and all others combined), and hospital supplemental insurance (HSI) type (no HSI = basic obligatory health insurance hospitalization only on the general ward in predefined hospitals within the canton of residence, ECO = basic HSI hospitalization on the general ward with free choice of hospital all over Switzerland, SP + P = semiprivate or private hospitalization in a double or single bedroom and free choice of hospital all over Switzerland).

The hospitals were characterized according to different levels as follows: level 1 university hospitals (L1 US), level 2 central service hospitals (L2 CSH), level 3 large regional service hospitals (L3 RSH-L), level 4 medium regional service hospitals (L4 RSH-M), and level 5 small regional service hospitals including some small specialized hospitals (L5 RSH-S). These levels are (except for L1 US) defined by the number of treated inpatients per year [15].

\section{Statistical Analysis}

The main statistical analysis follows the scheme described in the original study. In short, endpoints were described using frequencies and percentages in the case of categorical variables. Age was given as mean, median and standard deviation. The effect of age on the endpoints was evaluated, and for nonlinear associations age was divided into splines based on the segmented polynomial approach [16,17]. Multivariate logistic regressions were performed using a stepwise method to select statistically significant explanatory variables. Parameter estimates and odds ratios (ORs) were calculated including the Wald 95\% confidence intervals $(95 \% \mathrm{CI}) ; \mathrm{p}$ values were two-sided and considered significantly significant if $<0.05$. Given the explorative nature of this study, there was no adjustment for multiple testing. To test for effect dependency of the results for those patients with more than one hospitalization a model was evaluated including generalized estimating equation-based robust standard errors allowing for clustering by patient. All statistical analyses were performed with $\mathrm{SAS}^{\circledR}$, version 9.3 .

This study was approved by the ethics committees of the cantons BS/BL, TI, VS and ZH and the expert committee for data protection and professional confidentiality in medical research of the federal office of public health.

\section{Results}

Of the 2,086 patients included in this study, $7.2 \%(n=150)$ were hospitalized in two different and $0.6 \%(n=13)$ in 3 different hospitals during the last 30 days before death. Eighty percent of the patients died while hospitalized.

Overall most of the hospitalizations were in L2 CSH followed by L4 RSH-M (table 1). Except for L5 RSH-S, in all other hospital types more male than female patients were hospitalized. The distribution of the cancer types among the different hospital types was similar for levels 1-4. Only L5 RSH-S hospitals differed with fewer lung cancer patients and more breast cancer patients. The HSI type was quite uniformly distributed among the hospital types, with the highest proportion of patients without an HSI in the university hospitals. The distribution of hospital types by canton of residence reflects the available hospital types in the four cantons: VS and TI do not have a university hospital, and VS does not have L3 RSH-M hospitals. The 
Matter-Walstra et al.: Cancer-Related Therapies at the End of Life in Hospitalized Cancer Patients from Four Swiss Cantons: SAKK 89/09

Table 1. Descriptive statistics: demographic and geographic information by hospital type (in \%)

\begin{tabular}{|c|c|c|c|c|c|c|}
\hline & $\begin{array}{l}\text { All } \\
(n=2,262)\end{array}$ & $\begin{array}{l}\text { L1 US } \\
(n=287)\end{array}$ & $\begin{array}{l}\text { L2 CSH } \\
(n=865)\end{array}$ & $\begin{array}{l}\text { L3 RSH-L } \\
(n=434)\end{array}$ & $\begin{array}{l}\text { L4 RSH-M } \\
(\mathrm{n}=468)\end{array}$ & $\begin{array}{l}\text { L5 RSH-S } \\
(n=208)\end{array}$ \\
\hline Overall & & 12.7 & 38.2 & 19.2 & 20.7 & 9.2 \\
\hline \multicolumn{7}{|l|}{ Gender } \\
\hline Male & 54.6 & 55.1 & 57.8 & 52.5 & 56.0 & 41.3 \\
\hline Female & 45.4 & 44.9 & 42.2 & 47.7 & 44.0 & 58.6 \\
\hline \multicolumn{7}{|l|}{ Cancer diagnosis } \\
\hline Colon & 7.2 & 4.2 & 7.4 & 9.4 & 7.5 & 4.8 \\
\hline Hematologic & 7.5 & 10.1 & 6.1 & 8.1 & 9.2 & 4.3 \\
\hline Lung & 18.1 & 22.6 & 18.6 & 17.5 & 16.0 & 4.8 \\
\hline Mammary & 8.4 & 10.1 & 7.6 & 8.3 & 7.3 & 12.5 \\
\hline Prostate & 8.1 & 7.0 & 8.7 & 8.7 & 8.1 & 6.3 \\
\hline Other & 50.7 & 46.0 & 51.6 & 48.0 & 51.9 & 56.3 \\
\hline \multicolumn{7}{|l|}{ HSI status } \\
\hline None & 28.7 & 34.8 & 29.4 & 29.7 & 23.3 & 27.4 \\
\hline ECO & 39.6 & 33.5 & 42.1 & 41.9 & 38.0 & 36.1 \\
\hline $\mathrm{SP}+\mathrm{P}$ & 31.7 & 31.7 & 28.5 & 28.3 & 38.7 & 36.5 \\
\hline \multicolumn{7}{|l|}{ Canton of residence } \\
\hline $\mathrm{BS} / \mathrm{BL}$ & 11.4 & 21.3 & 11.8 & 10.8 & 0.2 & 22.1 \\
\hline $\mathrm{TI}$ & 26.8 & 0.3 & 28.8 & 12.9 & 51.7 & 28.4 \\
\hline VS & 6.2 & 0 & 6.6 & 0 & 17.5 & 1.0 \\
\hline $\mathrm{ZH}$ & 55.6 & 78.4 & 52.8 & 76.3 & 30.6 & 48.5 \\
\hline \multicolumn{7}{|l|}{ Age } \\
\hline Mean & 72.6 & 67.3 & 73.1 & 73.3 & 73.6 & 73.5 \\
\hline Median & 74 & 68 & 74 & 75 & 75 & 75 \\
\hline Standard deviation & 11.78 & 12.58 & 11.57 & 11.75 & 11.13 & 11.23 \\
\hline
\end{tabular}

Number of hospitalizations $=2,262$; number of patients $=2,086$.

mean age at death was similar among the hospital types, except for L1 US where the age at death was significantly lower (levels $2-5$, mean age 73 years; L1 US, mean age 67 years).

Of all episodes, $10.2 \%$ received inpatient ACDT and 22.2\% ANY ACDT within the last 30 days before death (table 2; fig. 1). ACDT (inpatient and ANY) was mostly given to patients with hematologic cancers (inpatient 17.8\%, ANY 29.6\%), having an SP + P HSI (inpatient 12.3\%, ANY 26.7\%), living in TI (inpatient 13.2\%, ANY 26.9\%) or being hospitalized in university hospitals (inpatient 18.5\%, ANY 33.4\%). Inpatient RT was given in 5.3\% and ANY in $11.7 \%$ of cases. Lung cancer patients received most RT (inpatient 7.8\%, ANY 16.8\%). The HSI type hardly influenced the proportion of cases receiving RT. In the two cantons with a university hospital (BS/BL and ZH), RT was given more frequently (inpatient and ANY) than in the two cantons without such a hospital type. Patients in university hospitals received most RT (inpatient $12.5 \%$, ANY 18.5\%). Inpatient $\mathrm{D}^{\mathrm{ao}} \mathrm{RT}$ was given in $14.7 \%$ and $\mathrm{ANY}$ in $30.9 \%$ of the cases. Lung cancer patients received most $\mathrm{D}^{\mathrm{ao}} \mathrm{RT}$ (inpatient $20.2 \%$, ANY 38.3\%), as well as patients with an SP + P HSI (inpatient 16.4\%, ANY 34.4\%), patients living in TI (inpatient 16.3\%, ANY 32.6\%) or patients being treated in L1 US hospitals (inpatient 28.6\%, ANY 46.3\%).

As already observed in the original study, receiving ACDT or RT was strongly age dependent. Until the death age of 65 years, a weak linear relationship between age and the probability of receiving ACDT was observed, followed by a clear linear decrease in therapy frequency after the death age of 65 years. A similar two-phase trend was observed for RT with a bend at the death age of 75 years (fig. 2). For this reason, multivariate logistic regression was performed using the spline methodology for age. 


\section{Oncology}

\begin{tabular}{l|l}
\hline Oncology 2015;88:18-27 & $\begin{array}{l}\text { () 2014 S. Karger AG, Basel } \\
\text { www.karger.com/ocl }\end{array}$ \\
\hline DOI: $10.1159 / 000367629$ &
\end{tabular}

Matter-Walstra et al.: Cancer-Related Therapies at the End of Life in Hospitalized

Cancer Patients from Four Swiss Cantons: SAKK 89/09

Table 2. Descriptive statistics: delivered cancer care

\begin{tabular}{|c|c|c|c|c|c|c|}
\hline & Inpatient ACDT & ANY ACDT & Inpatient RT & ANY RT & Inpatient $\mathrm{D}^{\mathrm{ao}} \mathrm{RT}$ & ANY D ${ }^{a o} R T$ \\
\hline All $(\mathrm{n}=2,262)$ & $10.2(8.9-11.4)$ & $22.2(20.5-24.0)$ & $5.2(4.3-6.1)$ & $11.7(10.3-13.0)$ & $14.7(13.2-16.1)$ & $30.9(29.0-32.8)$ \\
\hline \multicolumn{7}{|l|}{ Gender } \\
\hline Male $(n=1,234)$ & $9.7(8.1-11.4)$ & $22.4(20.1-24.8)$ & $5.4(4.2-6.7)$ & $13.0(11.1-14.8)$ & $14.3(12.4-16.3)$ & $32.1(29.5-34.7)$ \\
\hline Female $(\mathrm{n}=1,028)$ & $10.7(8.8-12.6)$ & $22.0(19.5-24.5)$ & $5.0(3.6-6.3)$ & $10.1(8.3-12.0)$ & $15.1(12.9-17.3)$ & $29.4(26.6-32.2)$ \\
\hline \multicolumn{7}{|l|}{ Cancer diagnosis } \\
\hline Colon $(n=162)$ & $9.3(4.8-13.7)$ & $25.9(19.2-32.7)$ & $6.2(2.5-9.9)$ & $9.3(4.8-13.7)$ & $13.6(8.3-18.9)$ & $32.1(24.9-39.3)$ \\
\hline Hematologic $(n=169)$ & $17.8(12.0-23.5)$ & $29.6(22.7-36.5)$ & $3.0(0.4-5.5)$ & $10.7(6.0-15.3)$ & $18.9(13.0-24.8)$ & $34.3(27.2-41.5)$ \\
\hline Lung $(\mathrm{n}=410)$ & $13.2(9.9-16.4)$ & $24.6(20.5-28.8)$ & $7.8(5.2-10.4)$ & $16.8(13.2-20.5)$ & $20.2(16.4-24.1)$ & $38.3(33.6-43.0)$ \\
\hline Mammary $(\mathrm{n}=191)$ & $14.7(9.6-19.7)$ & $28.3(21.9-34.7)$ & $4.2(1.3-7.0)$ & $9.9(5.7-14.2)$ & $17.8(12.4-23.2)$ & $35.1(28.3-41.9)$ \\
\hline Prostate $(\mathrm{n}=184)$ & $3.8(1.0-6.6)$ & $15.2(10.0-20.4)$ & $6.0(2.6-9.4)$ & $12.5(7.7-17.3)$ & $9.9(5.5-14.1)$ & $26.6(20.2-33.0)$ \\
\hline Other $(\mathrm{n}=1,146)$ & $8.4(6.8-10.0)$ & $19.9(17.6-22.2)$ & $4.5(3.3-5.7)$ & $10.5(8.7-12.2)$ & $12.5(10.6-14.4)$ & $27.5(24.9-30.1)$ \\
\hline
\end{tabular}

Figures are percentages with $95 \%$ CIs in parentheses.

For the multivariate logistic regression, only a minimal impact of clustering of inpatient episodes within patients with more than one episode (7.81\% of all patients) on standard errors was observed. Therefore, clustering was ignored in the final models.

The multivariate logistic regression for receiving inpatient ACDT showed significant effects for the variables (online suppl. table S2; fig. 3) age (decrease with increasing age), cancer type (prostate vs. lung cancer: $\mathrm{OR}=0.39,95 \% \mathrm{CI}=0.17-0.89$ ), canton of residence (TI vs. $\mathrm{ZH}$ : $\mathrm{OR}=1.93,95 \% \mathrm{CI}=1.34-2.78$ ), and hospital type (compared to central service hospitals: university hospital: $\mathrm{OR}=2.06,95 \% \mathrm{CI}=1.13-3.74$; medium regional hospitals: $\mathrm{OR}=1.66,95 \% \mathrm{CI}=1.08-2.56$; small regional hospitals: $\mathrm{OR}=0.39,95 \% \mathrm{CI}=0.162-0.933$ ). There was a significant interaction between hospital type and age indicating that the decrease in receiving ACDT with increasing age was significantly less prominent in the medium regional hospital type.

Considering the different cancer types, receiving ANY ACDT showed different results compared to receiving only inpatient ACDT, with colon $(\mathrm{OR}=1.89,95 \% \mathrm{CI}=1.14-3.14)$ and hematologic cancer patients $(\mathrm{OR}=1.93,95 \% \mathrm{CI}=1.19-3.15)$ having higher odds of receiving ANY ACDT than lung cancer patients (fig. 3). Patients living in the canton TI again showed significantly higher odds of receiving ANY ACDT $(\mathrm{OR}=1.69,95 \% \mathrm{CI}=1.30-2.21)$, as well as patients treated in university hospitals $(\mathrm{OR}=1.67,95 \% \mathrm{CI}=1.21-2.32)$. Patients treated in small regional hospitals once more had much lower odds of receiving ANY ACDT (OR $=0.38$, $95 \% \mathrm{CI}=0.23-0.63)$. In addition, patients with an SP + P HSI had a higher probability of receiving ANY ACDT (OR $=1.45,95 \% \mathrm{CI}=1.10-1.91)$. A significant interaction between age and cancer type was observed demonstrating that with increasing age the differences between the cancer types became more prominent than at a younger age.

Inpatient and ANY RT was only significantly influenced by age and hospital type for patients hospitalized in smaller hospitals (levels 3-5) having lower odds of receiving RT (no inpatient RT in regional medium-sized hospitals; fig. 3).

Receiving inpatient or ANY D ${ }^{\text {ao }} \mathrm{RT}$ was significantly influenced by age, cancer type, canton of residence and hospital type (fig. 3). Patients living in TI had significantly higher odds of receiving $\mathrm{D}^{\mathrm{a} o} \mathrm{RT}$ during the last 30 days before death (inpatient: $\mathrm{OR}=1.61,95 \% \mathrm{CI}=1.18-$ 2.19; $\mathrm{ANY}$ : $\mathrm{OR}=1.38,95 \% \mathrm{CI}=1.09-1.75$ ). In addition, patients treated in university hospitals had significantly higher odds of receiving $\mathrm{D}^{\mathrm{ao}} \mathrm{RT}$ (inpatient: $\mathrm{OR}=1.83,95 \% \mathrm{CI}=1.30-2.59$; ANY: $\mathrm{OR}=1.45,95 \% \mathrm{CI}=1.08-1.94$ ), while the odds decreased for the smaller regional hospital types (levels 3-5). 
Matter-Walstra et al.: Cancer-Related Therapies at the End of Life in Hospitalized Cancer Patients from Four Swiss Cantons: SAKK 89/09

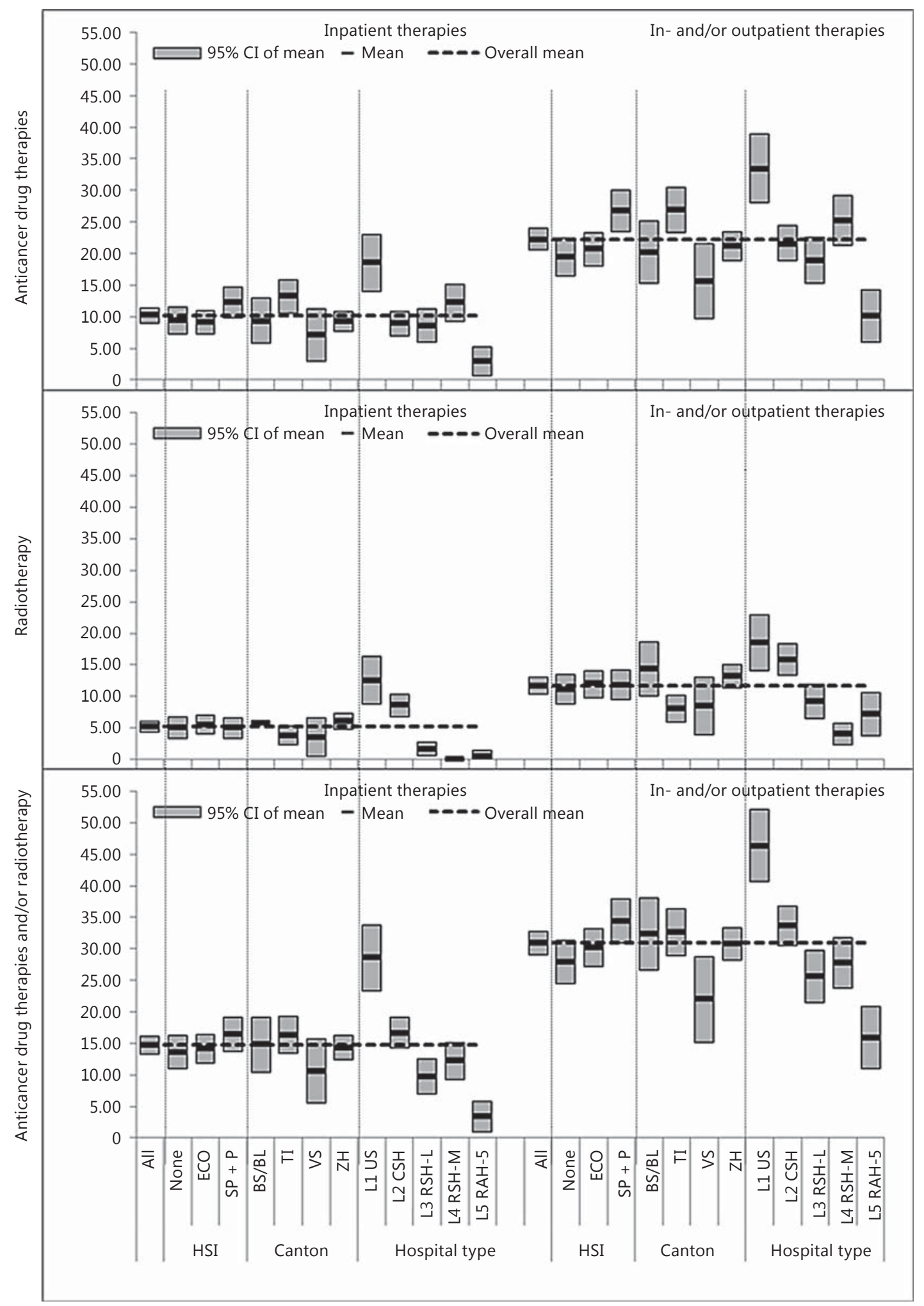

Fig. 1. Descriptive statistics for cancer therapies by HSI status, canton of residence and hospital type. 


\section{Oncology}

\begin{tabular}{l|l}
\hline Oncology 2015;88:18-27 \\
\hline DOI: $10.1159 / 000367629$ & $\begin{array}{l}\text { ( 2)14 S. Karger AG, Basel } \\
\text { www.karger.com/ocl }\end{array}$ \\
\hline
\end{tabular}

Matter-Walstra et al.: Cancer-Related Therapies at the End of Life in Hospitalized Cancer Patients from Four Swiss Cantons: SAKK 89/09

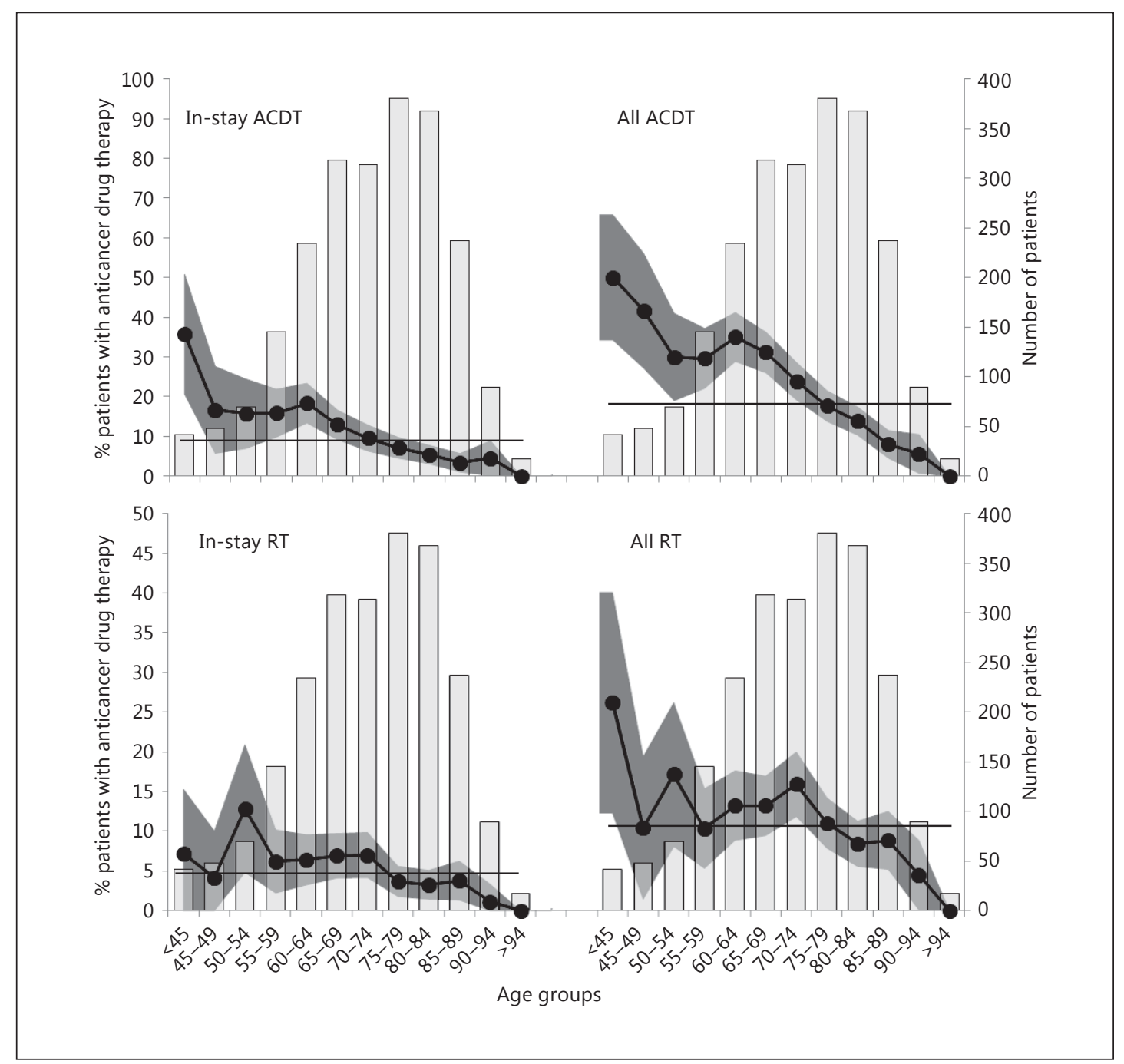

Fig. 2. Effect of age on therapies. Shaded area $=95 \% \mathrm{CI}$; curve $=\%$ patients; straight line $=$ mean.

\section{Discussion}

Overall the frequency of delivered in- and outpatient cancer therapies $(30.9 \%$ of the episodes) in four Swiss cantons was similar to the values found in other studies $[18,19]$ and was $10 \%$ higher than seen in the total cohort as described in the original study [14]. In addition, we found that within Switzerland the probability of receiving ACDT, or ACDT and/ or RT (inpatient and ANY), during the last 30 days before death not only differed by cancer type and age, but also between treating hospital types and canton of residence. Different treatment intensities can be expected for different cancer types [20] or they might decrease with age. However, significant differences in the intensity of care between hospitals and cantons may hint at under- or overtreatment issues. Especially, the significantly higher odds of receiving cancer-related cancer care in a canton without a university hospital should trigger discussions.

In the original study, the HSI status played a significant role in the treatment received (in- and/or outpatient ACDT as well as ACDT and/or RT). Yet, in this cohort of patients with 


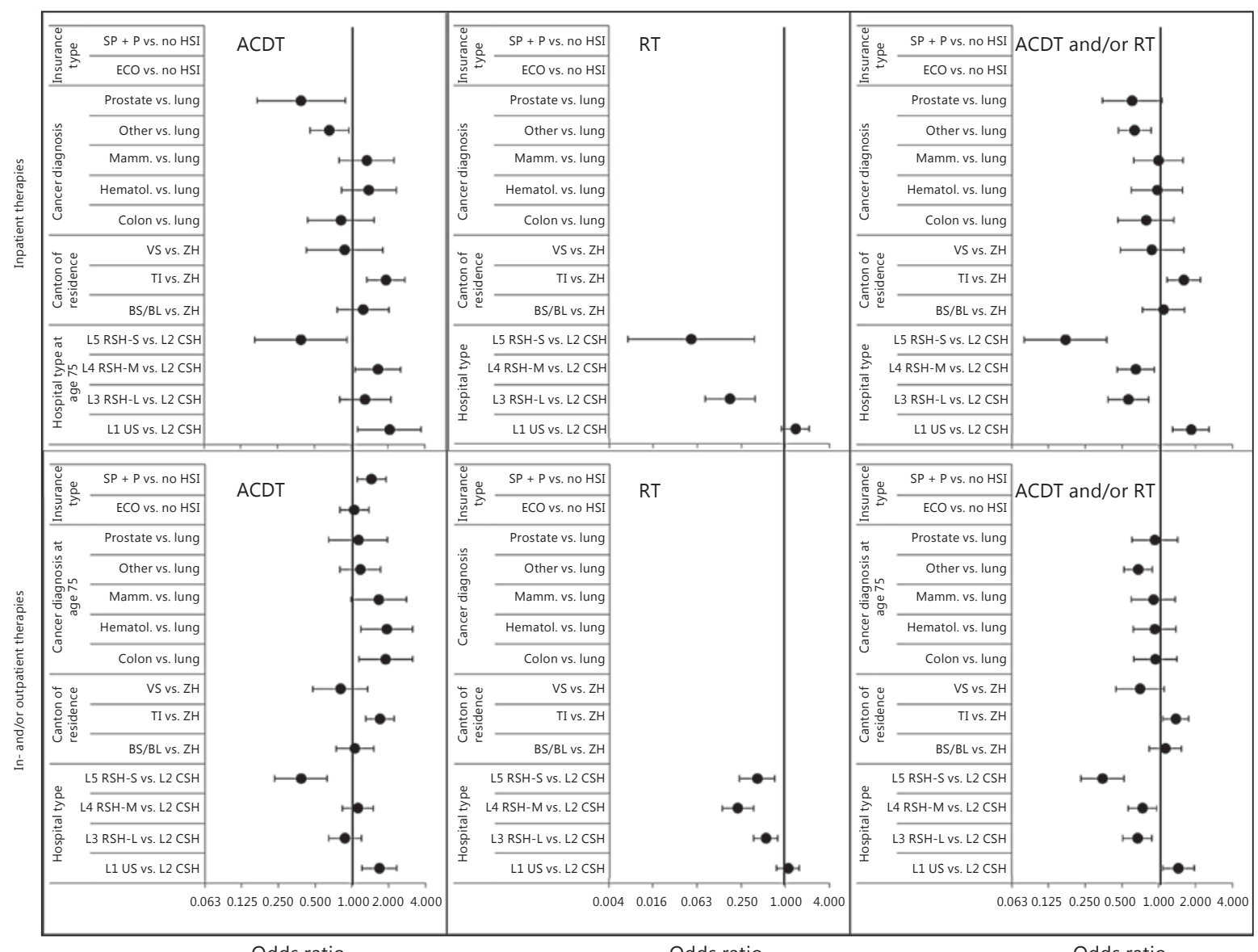

Odds ratio

Odds ratio

Odds ratio

Fig. 3. Multivariate logistic regression: ORs for significant explorative variables for in- and outpatient cancer therapies. Mamm. = Mammary; hematol. = hematologic.

a known cause of death, this factor only plays a significant role for the combined in- and outpatient ACDT outcome, where patients with an SP + P HSI show a significantly higher probability of receiving such a therapy. For the solely inpatient outcomes, the insurance status did not have a significant effect. One reason might be that the influence of the hospital type masks the effect of the insurance status, as more patients with an SP + P HSI are hospitalized in medium and small regional hospital types. Overall these findings are somewhat similar to those reported by Keating et al. [21], who showed that patients treated in a private setting had a higher probability of receiving ACDT during the last 2 weeks before death.

The effect of the hospital type on the intensity of end-of-life care is understudied and the existing literature is conflicting. Whereas some studies found an influence of the hospital type on the delivered care at the end of life [22, 23], others did not show such effects [21, 24]. In our study, we showed that being hospitalized in 2 out of a total of 5 university hospitals in Switzerland significantly increases the odds of receiving any kind of cancer-related therapies (inpatient and ANY). A second peculiarity is that patients hospitalized in medium-sized regional hospitals show second highest odds of receiving inpatient ACDT. As none of these hospitals seems to provide RT, one might ask whether the absence of RT facilities is compensated by delivering more ACDT.

This study has some limitations. One of them is that only cancer patients who had been hospitalized during the last 30 days before death were included in the analysis. Patients not 


\section{Oncology}

\begin{tabular}{l|l}
\hline Oncology 2015;88:18-27 \\
\hline DOI: 10.1159/000367629 & $\begin{array}{l}\text { @ 2014 S. Karger AG, Basel } \\
\text { www.karger.com/ocl }\end{array}$ \\
\hline
\end{tabular}

Matter-Walstra et al.: Cancer-Related Therapies at the End of Life in Hospitalized Cancer Patients from Four Swiss Cantons: SAKK 89/09

hospitalized during the last month before death (approx. $\pm 30 \%$ of the original cohort) could not be explicitly identified as dying from cancer because of missing exclusive cause of death information. Therefore, the observed numbers might be too high as they only refer to patients hospitalized during the last 30 days before death. Not hospitalized cancer patients may not have received any cancer-related therapy during this period. Furthermore, selection bias due to a limited number of cantons being included as well as the use of data from only one insurance company may limit conclusions. Although cancer-related outpatient therapies are mostly initiated in a hospital and given in an ambulatory setting, we were not able to identify whether the received outpatient therapies were directly related to/initiated by the hospital in which the patients stayed. Another uncertainty is whether or not referral to the different hospital types (therefore, expected treatment) is related to the clinical condition and personal preferences of the patients.

Research on end-of-life cancer care, especially in Europe, has only emerged during the last two decades and still receives only minimal financial support [25]. The importance of such research is evident, as disparities between countries, within countries and among different patient populations do matter on many levels such as quality of care issues [26-31], economical aspects [32-34] or shifts in the delivery of care over time [35].

\section{Conclusion}

As shown in this study, for Swiss cancer patients hospitalized during the last 30 days before death, the probability of receiving cancer-related therapies depends on age, cancer type, canton of residence and hospital type. These results should serve as a basis for discussions among oncologists in Switzerland and may question the compliance with standard of care guidelines for terminal cancer patients. Furthermore, the results of this study may serve as a bench mark. In 2012, the Swiss health care system changed to the Swiss DRGs. The effect of this change on the delivery of health care can be investigated in the near future comparing pre- and post-2012 data.

\section{Acknowledgements}

This work was supported by the Swiss Cancer Research Foundation KLS-02738-02-2011, end-of-life patterns of care in Swiss cancer patients (EOL - SAKK 89/10).

\section{Disclosure Statement}

The authors have no conflicts of interest to declare.

\section{References}

1 Earle CC, Landrum MB, Souza JM, et al: Aggressiveness of cancer care near the end of life: is it a quality-of-care issue? J Clin Oncol 2008;26:3860-3866.

$\checkmark 2$ Meeussen K, Van den Block L, Echteld MA, et al: End-of-life care and circumstances of death in patients dying as a result of cancer in Belgium and the Netherlands: a retrospective comparative study. J Clin Oncol 2011;29: 4327-4334.

-3 Toole M, Lutz S, Johnstone PA: Radiation oncology quality: aggressiveness of cancer care near the end of life. J Am Coll Radiol 2012; 9:199-202.

4 Guadagnolo BA, Liao KP, Elting L, et al: Use of radiation therapy in the last 30 days of life among a large population-based cohort of elderly patients in the United States. J Clin Oncol 2013;31:80-87. 


\section{Oncology}

\begin{tabular}{l|l}
\hline Oncology 2015;88:18-27 & \\
\hline DOI: 10.1159/000367629 & $\begin{array}{l}\text { @ 2014 S. Karger AG, Basel } \\
\text { www.karger.com/ocl }\end{array}$ \\
\hline
\end{tabular}

Matter-Walstra et al.: Cancer-Related Therapies at the End of Life in Hospitalized

Cancer Patients from Four Swiss Cantons: SAKK 89/09

5 Pardon K, Chambaere K, Pasman HR, et al: Trends in end-of-life decision making in patients with and without cancer. J Clin Oncol 2013;31:1450-1457.

6 Earle CC: Trends in the aggressiveness of cancer care near the end of life. J Clin Oncol 2003;22:315-321.

7 Earle CC: Patterns of care studies: creating 'an environment of watchful concern'. J Clin Oncol 2003;21:44794480.

8 Harrington SE, Smith TJ: The role of chemotherapy at the end of life: 'when is enough, enough?'. JAMA 2008; 299:2667-2678.

-9 Grunfeld E, Lethbridge L, Dewar R, et al: Towards using administrative databases to measure populationbased indicators of quality of end-of-life care: testing the methodology. Palliat Med 2006;20:769-777.

10 Grunfeld E, Urquhart R, Mykhalovskiy E, et al: Toward population-based indicators of quality end-of-life care: testing stakeholder agreement. Cancer 2008;112:2301-2308.

11 Ho TH, Barbera L, Saskin R, et al: Trends in the aggressiveness of end-of-life cancer care in the universal health care system of Ontario, Canada. J Clin Oncol 2011;29:1587-1591.

-12 Shugarman LR, Bird CE, Schuster CR, Lynn J: Age and gender differences in medicare expenditures and service utilization at the end of life for lung cancer decedents. Womens Health Issues 2008;18:199-209.

13 Smith AK, Earle CC, McCarthy EP: Racial and ethnic differences in end-of-life care in fee-for-service Medicare beneficiaries with advanced cancer. J Am Geriatr Soc 2009;57:153-158.

14 Matter-Walstra KM, Achermann R, Rapold R, et al: Delivery of health care at the end of life in cancer patients of four Swiss cantons: a retrospective database study (SAKK 89/09). BMC Cancer 2014;14:306-317.

15 BFS: Hospital typology. 2006. http://www.bfs.admin.ch/bfs/portal/de/index/infothek/erhebungen_ quellen/blank/blank/kh/02.Document.86653.pdf.

16 Jamrozik J, Bohmanova J, Schaeffer LR: Selection of locations of knots for linear splines in random regression test-day models. J Anim Breed Genet 2010;127:87-92.

17 Smith PL: Splines as a useful and convenient statistical tool. Am Stat 1979;33:57-62.

18 Emanuel EJ, Young-Xu Y, Levinsky NG, et al: Chemotherapy use among Medicare beneficiaries at the end of life. Ann Intern Med 2003;138:639-643.

19 Earle CC, Neville BA, Landrum MB, et al: Trends in the aggressiveness of cancer care near the end of life. J Clin Oncol 2004;22:315-321.

20 Seow H, Barbera L, Sutradhar R, et al: Trajectory of performance status and symptom scores for patients with cancer during the last six months of life. J Clin Oncol 2011;29:1151-1158.

21 Keating NL, Landrum MB, Lamont EB, et al: End-of-life care for older cancer patients in the Veterans Health Administration versus the private sector. Cancer 2010;116:3732-3739.

22 Morishima T, Lee J, Otsubo T, et al: Impact of hospital case volume on quality of end-of-life care in terminal cancer patients. J Palliat Med 2013;16:173-178.

23 Sacerdote C, Baldi I, Bertetto 0, et al: Hospital factors and patient characteristics in the treatment of colorectal cancer: a population based study. BMC Public Health 2012;12:775.

24 Morden NE, Chang CH, Jacobson JO, et al: End-of-life care for Medicare beneficiaries with cancer is highly intensive overall and varies widely. Health Aff (Millwood) 2012;31:786-796.

25 Sigurdardottir KR, Haugen DF, Bausewein C, et al: A pan-European survey of research in end-of-life cancer care. Support Care Cancer 2012;20:39-48.

-26 Earle CC, Park ER, Lai B, et al: Identifying potential indicators of the quality of end-of-life cancer care from administrative data. J Clin Oncol 2003;21:1133-1138.

27 Lorenz K, Lynn J, Dy S, et al: Cancer care quality measures: symptoms and end-of-life care. Evid Rep Technol Assess (Full Rep) 2006;137:1-77.

28 Ostgathe C, Voltz R: Quality indicators in end-of-life care. Curr Opin Support Palliat Care 2010;4:170-173.

29 Seow H, Snyder CF, Mularski RA, et al: A framework for assessing quality indicators for cancer care at the end of life. J Pain Symptom Manage 2009;38:903-912.

30 Tang ST, Wu SC, Hung YN, et al: Trends in quality of end-of-life care for Taiwanese cancer patients who died in 2000-2006. Ann Oncol 2009;20:343-348.

31 Gielen B, Remacle A, Mertens R: Patterns of health care use and expenditure during the last 6 months of life in Belgium: differences between age categories in cancer and non-cancer patients. Health Policy 2010;97:53-61.

32 Tan TS, Jatoi A: End-of-life hospital costs in cancer patients: do advance directives or routes of hospital admission make a difference? Oncology 2011;80:118-122.

-33 Walker H, Anderson M, Farahati F, et al: Resource use and costs of end-of-Life/palliative care: Ontario adult cancer patients dying during 2002 and 2003. J Palliat Care 2011;27:79-88.

34 Zhang B, Wright AA, Huskamp HA, et al: Health care costs in the last week of life: associations with end-of-life conversations. Arch Intern Med 2009;169:480-488.

35 Teno JM, Gozalo PL, Bynum JP, et al: Change in end-of-life care for Medicare beneficiaries: site of death, place of care, and health care transitions in 2000, 2005, and 2009. JAMA 2013;309:470-477. 